\title{
Tobacco taxes as a tobacco control strategy
}

\author{
Frank J Chaloupka, ${ }^{1}$ Ayda Yurekli, ${ }^{2}$ Geoffrey T Fong ${ }^{3}$
}

${ }^{1}$ Department of Economics, University of Illinois at Chicago, Chicago, Illinois, USA

${ }^{2}$ World Health Organization, Geneva, Switzerland

${ }^{3}$ Department of Psychology, University of Waterloo, Waterloo, Ontario, Canada

\section{Correspondence to}

Professor Frank J Chaloupka, Economics, University of Illinois at Chicago, Institute for Health Research and Policy, University of Illinois at Chicago, Chicago, IL 60608, USA; fjc@uic.edu

Received 31 December 2011 Accepted 4 January 2012

\author{
ABSTRACT \\ Background Increases in tobacco taxes are widely \\ regarded as a highly effective strategy for reducing \\ tobacco use and its consequences.
}

Methods The voluminous literature on tobacco taxes is assessed, drawing heavily from seminal and recent publications reviewing the evidence on the impact of tobacco taxes on tobacco use and related outcomes, as well as that on tobacco tax administration.

Results Well over 100 studies, including a growing number from low-income and middle-income countries, clearly demonstrate that tobacco excise taxes are a powerful tool for reducing tobacco use while at the same time providing a reliable source of government revenues. Significant increases in tobacco taxes that increase tobacco product prices encourage current tobacco users to stop using, prevent potential users from taking up tobacco use, and reduce consumption among those that continue to use, with the greatest impact on the young and the poor. Global experiences with tobacco taxation and tax administration have been used by WHO to develop a set of 'best practices' for maximising the effectiveness of tobacco taxation.

Conclusions Significant increases in tobacco taxes are a highly effective tobacco control strategy and lead to significant improvements in public health. The positive health impact is even greater when some of the revenues generated by tobacco tax increases are used to support tobacco control, health promotion and/or other health-related activities and programmes. In general, oppositional arguments that higher taxes will have harmful economic effects are false or overstated.

\section{INTRODUCTION}

'Sugar, rum, and tobacco, are commodities which are no where necessaries of life, which are become objects of almost universal consumption, and which are therefore extremely proper subjects of taxation. ${ }^{1}$

For centuries, governments around the world have heeded Adam Smith's advice, imposing a variety of taxes on tobacco leaf and tobacco products. Governments have used these taxes in the pursuit of multiple goals. Historically, and still the case in many countries, the primary motivation for taxing tobacco has been revenue generation. ${ }^{2}$ Tobacco products are a reliable source of revenue given that they are typically produced by a small number of manufacturers, have few good substitutes and, at least in the short run, have relatively inelastic demand. Some governments have levied high import duties on tobacco leaf and/or tobacco products as a way of protecting domestic tobacco farmers and manufacturers from foreign competitors. Others have imposed differential taxes on tobacco products that are higher on the products produced by multinational tobacco companies than on those made by local producers. Still others have kept taxes low on at least some products so as to keep them affordable for the poor, while generating revenues by taxing premium products at much higher rates.

Over the past 50 years, the accumulation of evidence on the health and economic consequences of tobacco use has led numerous governments, first in high-income countries and more recently in a growing number of low-income and middleincome countries, to significantly increase tobacco taxes in efforts to reduce tobacco use. These efforts have been strengthened by the growth of economic and other research demonstrating the effectiveness of higher tobacco product taxes and prices in reducing tobacco use. This research provided the strong evidence base supporting the WHO's Framework Convention on Tobacco Control (WHO FCTC) call for governments to use higher tobacco taxes to reduce tobacco use as a way to achieve their health objectives. ${ }^{3}$ As countries have become signatories to the treaty, several have adopted significant increases in their tobacco taxes as a way to reduce tobacco use and the death, disease and economic costs that it causes.

This paper reviews the salient issues related to the effectiveness of tobacco taxation as a tobacco control strategy. We begin with an overview of the different types of tobacco taxes and tax structures used by governments around the world and discuss how these taxes impact on the prices of tobacco products. This is followed by a concise review of the research evidence on the impact of tobacco taxes and prices on tobacco use, as well as the added impact in reducing tobacco use that results from dedicating tobacco tax revenues to other tobacco control efforts. We then briefly discuss the evidence on the variety of arguments used in opposition to tobacco taxation.

Based on this, we highlight 'best practices' for using tobacco taxes for tobacco control. Given the voluminous literature on tobacco taxes, we draw heavily from seminal and recent publications reviewing the evidence on the impact of tobacco taxes on tobacco use and related outcomes, as well as that on tobacco tax administration, including: the World Bank's policy report Curbing the Epidemic: Governments and the Economics of Tobacco Control and several of the report's background papers contained in Tobacco Control in Developing Countries (both available online at http://www.worldbank.org/tobacco); the International Agency for Research on Cancer's Handbooks of Cancer Prevention, Volume 14: Effectiveness of Tax and Price Policies for Tobacco Control (available online at: http://www.iarc.fr/en/publications/ 
list/handbooks); and the WHO Technical Manual on Tobacco Tax Administration (available online at: http://www.who.int/tobacco/ publications/tax_administration/en/index.html). ${ }^{2}$ 4-6

\section{TOBACCO TAXES: TYPES, LEVELS, STRUCTURES AND ADMINISTRATION}

(NB This section draws heavily from WHO's Technical Manual on Tobacco Tax Administration.) $)^{2}$ Governments impose a variety of taxes on tobacco and tobacco products. Some apply to tobacco leaf, such as a tax on the value of the tobacco crop and duties on imports and/or exports of tobacco leaf. Most governments assess taxes on tobacco products. These taxes include: excise taxes, value added taxes (VAT), general sales taxes, duties on tobacco product imports and/or exports and/or other special taxes. Of these, tobacco product excise taxes (including other taxes specifically applied to tobacco products but called by other names) are most important for achieving the health objective of reduced tobacco consumption since these are the taxes that are uniquely applied to tobacco products and that raise the prices of these products relative to the prices of other goods and services.

Most governments levy excise taxes and other taxes on tobacco products and apply duties to imported tobacco products. (When referring to excise taxes, this paper includes other taxes uniquely applied to tobacco products, but called by other names (eg, the 'consumption tax' levied on cigarettes in China and the distinct general sales tax rates applied to tobacco products in Egypt).) Based on available data, about $90 \%$ of countries impose tobacco excise taxes, almost as many apply a VAT or sales tax to tobacco products, and nearly all impose import duties. ${ }^{2}$ Countries that do not levy tobacco excises include those in the Gulf Cooperation Council, some Pacific Island and Caribbean island countries, and a few others; in many of these countries, there is little or no domestic tobacco production and governments generate tobacco revenues through duties on imported tobacco products. VAT rates vary widely, ranging from $2 \%$ to $20 \%$ in the countries that apply a VAT to tobacco products. Similarly, import duties on tobacco products vary widely with rates of more than $100 \%$ of importers' declared CIF (cost, insurance, freight) value in some countries.

Because of their importance in raising the prices of tobacco products relative to the prices of other goods and services, tobacco product excise taxes are most important for tobacco control. There are two types of excise taxes: specific and ad valorem. A specific excise tax is levied based on quantity (eg, a fixed amount per cigarette or weight of tobacco), while an ad valorem excise is levied based on value (eg, a percentage of the factory price or retail price). Tobacco product excises are generally, but not always, applied early in the distribution chain (on manufacturers or distributors).

The level and type of excise tax applied to tobacco products varies widely across countries. Figure 1 illustrates the variation in the average excise tax applied to cigarettes (in purchasing power parity (PPP) adjusted US\$), the average price of the most widely sold brand of cigarettes (in PPP US\$) and the percentage of cigarette price accounted for by excise and other taxes levied on tobacco products for countries grouped by income level. As the figure illustrates, there is a direct relationship between the level of the cigarette excise tax and the level of cigarette prices, with higher taxes resulting in higher prices. In addition, a clear relationship exists between taxes, prices and income levels, with the average price, average excise tax and tax as a share of price falling as income falls. Globally, excise and other taxes applied to cigarettes account for a little over half of the average price of cigarettes, falling from $65.5 \%$ in high-income countries to $40.8 \%$ in low-income countries. Similarly, the average price falls from nearly PPP US $\$ 5.00$ per pack in high-income countries to almost PPP US\$2.00 per pack in low-income countries. Considerable variation in taxes exists within income group, as well as across regions (see figure 2$)^{7}$

In addition to the variability across countries, excise taxes applied to cigarettes vary within a country as the amount and type of excise tax depends on value, characteristics of the cigarette and other factors. ${ }^{2}$ Australia, South Africa and many other countries levy a uniform specific excise tax on all cigarettes, while India, the Philippines and others apply a tiered tax structure that imposes differential specific excises that vary based on manufacturers' prices, production scale, whether or not the cigarette is filtered, cigarette length, or other factors. Similarly, Vietnam and other countries levy a uniform ad valorem excise tax on all cigarettes, while Bangladesh and others impose differential ad valorem taxes based on price or other factors. In the European Union and several others, both types of excises are applied, with some of these varying the specific tax level and/or ad valorem tax rate based on cigarette prices, characteristics or other factors. Finally, Egypt, Turkey and a few other countries apply a minimum tax to lower priced cigarette brands, with some variation of the tax structures described above applied to higher priced brands. As summarised in table 1, the type of excise tax applied to cigarettes varies by income level and by region.

Similarly, there is considerable variation across and within countries in the level and structure of taxes applied to other
Figure 1 Simple average price of the most sold brand in international dollars (PPP), excise tax per pack and total tax share by income group, $2010 .^{7}$ Total tax share includes excise taxes and other taxes (eg, VAT) applied to tobacco products.

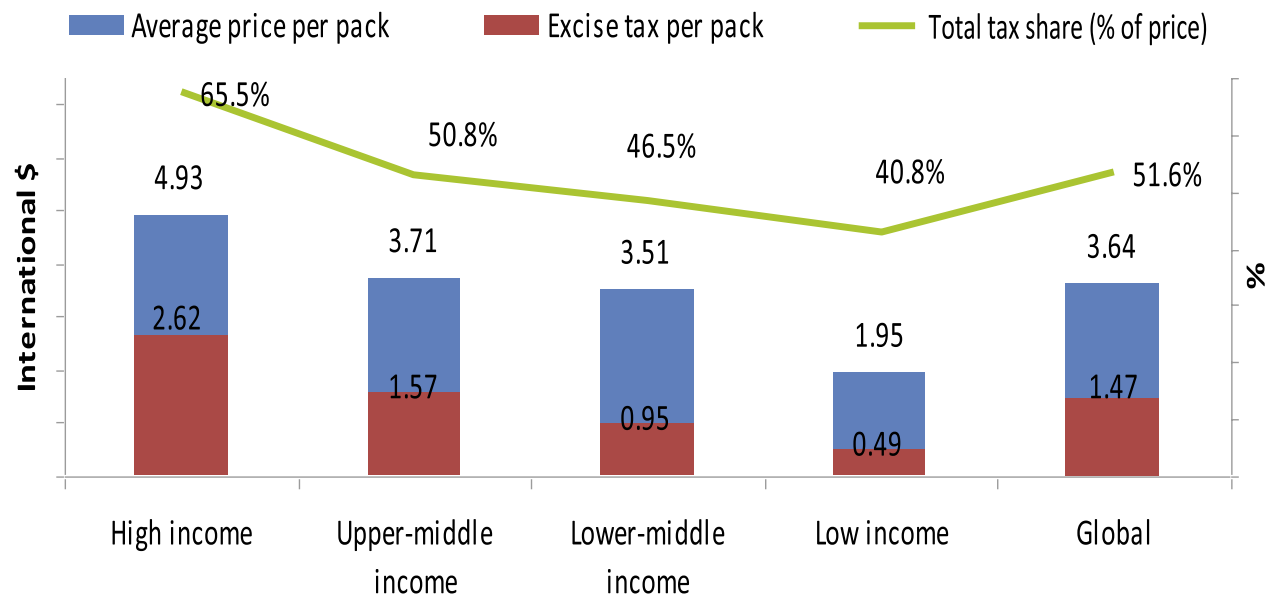


Figure 2 Simple average price of the most sold brand in international dollars (PPP), excise tax per pack and total tax share by WHO region, $2010 .^{7}$ Column labels refer to WHO regional offices for Africa (AFRO), the Americas (AMRO), the Eastern Mediterranean (EMRO), Europe (EURO), South-East Asia (SEARO) and the Western Pacific (WPRO). Total tax share includes excise taxes and other taxes (eg, VAT) applied to tobacco products.

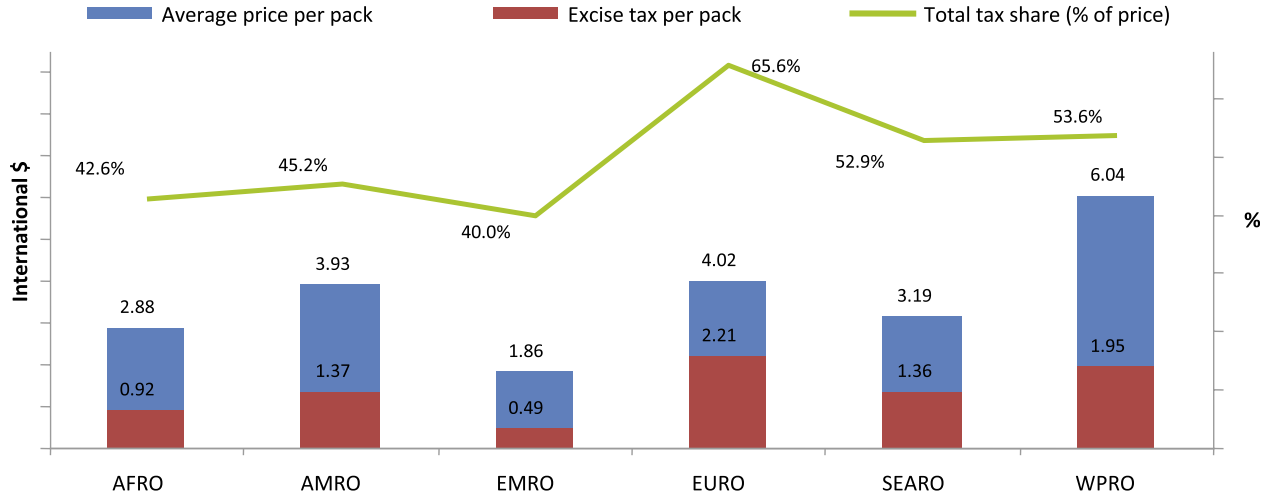

tobacco products. The variability in tobacco excises reflects that influence of different interest groups with different objectives, which may include: revenue generation; protection of domestic tobacco growers and/or manufacturers; keeping at least some tobacco products affordable to the poor; and protecting public health. Some governments, such as the US Federal Government, set their tobacco excises on different tobacco products so that the excises are similar across all products. Others, including most US states, apply different excises to different types of tobacco products so that the resulting share of price accounted for by tax varies widely across products. Still others employ very complex systems with different taxes applied to different brands and products based on price, type of product, product characteristics and other factors. For example, taxes in Indonesia have historically differed for manufactured cigarettes and kreteks, with lower taxes applied to the products of smaller scale manufacturers in an apparent effort to provide a competitive advantage to smaller, domestic firms over larger multinational tobacco companies. Likewise, Turkey once taxed cigarettes containing at least two-thirds oriental tobacco at lower rates than other cigarettes in an effort to protect its local tobacco monopoly from foreign competition and to increase the demand for oriental tobacco that was largely grown in Turkey. In some countries, some tobacco products are exempted completely or almost completely from tobacco excises. For example, bidis are largely untaxed in India given perceived difficulties in collecting these

Table 1 The types of cigarette excise taxes applied by income group and WHO region ${ }^{2}$

\begin{tabular}{lllllll}
\hline & \multicolumn{2}{l}{ Excise system on cigarettes } & & \\
\cline { 2 - 5 } $\begin{array}{l}\text { Income } \\
\text { group }\end{array}$ & $\begin{array}{l}\text { Only } \\
\text { specific }\end{array}$ & $\begin{array}{l}\text { Only ad } \\
\text { valorem }\end{array}$ & $\begin{array}{l}\text { Specific and } \\
\text { ad valorem }\end{array}$ & $\begin{array}{l}\text { No } \\
\text { excise }\end{array}$ & $\begin{array}{l}\text { Total } \\
\text { countries* }\end{array}$ \\
\hline High & 11 & 2 & 25 & 7 & 45 \\
Upper middle & 16 & 11 & 9 & 6 & 42 \\
Lower middle & 18 & 19 & 12 & 3 & 52 \\
Low & 10 & 28 & 2 & 3 & 43 \\
By region: & & & & & \\
$\quad$ AFRO & 14 & 29 & 1 & 2 & 46 \\
$\quad$ AMRO & 13 & 16 & 2 & 3 & 34 \\
EMRO & 1 & 7 & 5 & 7 & 20 \\
$\quad$ EURO & 10 & 3 & 36 & 0 & 49 \\
SEARO & 3 & 2 & 2 & 1 & 8 \\
$\quad$ WPRO & 14 & 3 & 2 & 6 & 25 \\
All countries & 55 & 60 & 48 & 19 & 182 \\
\hline
\end{tabular}

Column labels refer to WHO regional offices for Africa (AFRO), the Americas (AMRO), the Eastern Mediterranean (EMRO), Europe (EURO), South-East Asia (SEARO) and the Western Pacific (WPRO).

*Countries for which data are available. taxes from the large number of small producers and concerns about the regressive nature of a bidi tax.

In addition to being more difficult to administer, a more complex tax structure will undermine the health impact of tobacco excise taxes by creating greater opportunities for tax avoidance and tax evasion. In addition, more complex tax structures lead to significantly greater variability in the prices of tobacco products, which creates opportunities for substitution to cheaper brands/products in response to increased taxes (see table 2). Similarly, ad valorem excises on tobacco products will be less effective than specific excise taxes in achieving health objectives. Ad valorem tobacco excises are more difficult to administer, increase opportunities for tax avoidance and evasion, and create greater gaps in prices between high and low priced brands. $^{8}$ In addition to undermining the health impact of tobacco excises, more complex tax structures and/or greater reliance on ad valorem excises will also weaken the revenue impact of these taxes and increase the uncertainty of revenue projections, given the greater tax avoidance and evasion, opportunities for substitution to cheaper brands/products and dependence on industry pricing decisions.

In the future, differential taxation for different tobacco products may make sense from a harm-reduction perspective, when coupled with effective tobacco product regulation that results in significantly reduced-risk tobacco products being marketed. A differential tax structure that taxes the significantly reduced-risk products at lower rates than riskier products would likely lead many who currently use the most dangerous products to switch to the new, significantly reduced-risk ones. This type of differential treatment might work best in the short term, accelerating the transition from the most harmful products to reduced-risk products; over time, the differential treatment could be eliminated to reduce all tobacco product use. However, given the current evidence on the relative risks of different tobacco products, differential taxation based on RR is highly controversial and adopting this strategy could have unanticipated public health consequences.

Table 2 Excise tax structure and average cigarette prices

\begin{tabular}{lll}
\hline Excise tax structure & $\begin{array}{l}\text { Average } \\
\text { price PPP }\end{array}$ & $\begin{array}{l}\text { Excise } \\
\text { tax PPP }\end{array}$ \\
\hline Only specific & 4.51 & 1.78 \\
Only ad valorem & 2.38 & 0.77 \\
Mix system & 3.81 & 2.17 \\
$\quad$ Relying more on specific & 4.42 & 2.54 \\
Relying more on ad valorem & 3.40 & 1.91 \\
\hline
\end{tabular}

Source: WHO, unpublished data 


\section{TAX, PRICE AND TOBACCO USE}

Economists and other researchers have taken advantage of the extensive variation in tobacco taxes across and within countries as well as over time to examine the impact of tobacco product taxes and prices on tobacco use. (See IARC Handbook 14 for a comprehensive review of the research discussed in this section.) ${ }^{6}$ Prior to the publication of the World Bank's Curbing the Epidemic, nearly all studies came from high-income countries. ${ }^{4}$ These studies consistently found that increases in taxes and prices on tobacco products lead to reductions in tobacco use. The vast majority of studies from high-income countries have produced estimates of price elasticity (the percentage reduction in consumption resulting from a $1 \%$ increase in price) in the range of -0.25 to -0.5 , with most clustered around $-0.4 .^{9-11}$ Several modelled the addictive nature of tobacco use, finding that tobacco demand is more price responsive in the long run than in the short run. ${ }^{12} 13$

Over the past decade, many studies have examined the impact of taxes and prices on tobacco use in low-income and middleincome countries. These studies produce a wide range of estimated price elasticities, with most, but not all, indicating that demand for tobacco products in low-income and middle-income countries is at least as responsive, and often more responsive, to price than it is in high income countries. For example, $\mathrm{Hu}$ and Mao estimated that the price elasticity of cigarette demand in China ranges from -0.50 to -0.64 , while John estimated price elasticities in the range from -0.86 to -0.92 for bidis and -0.18 to -0.34 for cigarettes in India. ${ }^{14} 15$

Findings from studies based on survey data of adult tobacco use show that taxes and prices influence the prevalence of tobacco use and amount of tobacco consumed by users. In general, estimates from high-income countries suggest that about half of the impact of price on tobacco use results from its effect on prevalence, largely reflecting cessation among adult users. ${ }^{16} 17$ This is confirmed by studies that find that increases in prices lead current users to try to quit, with some successful in doing so in the long run. ${ }^{18} 19$ Comparable studies from lowincome and middle-income countries also find that cigarette prices affect prevalence and intensity of cigarette smoking, although the relative impact on prevalence and consumption varies considerably across studies/countries. ${ }^{20} 21$

Several studies have examined the differential responses to price of population subgroups, including those based on age, gender, income, education, race/ethnicity and location (urban vs rural). Consistent patterns are evident with respect to differences by age and socioeconomic status (SES). Studies looking at tobacco use among adolescents and young adults find that young people are two to three times more responsive to tax and price than are older persons, with higher taxes and prices particularly effective in keeping young people from moving beyond experimentation with tobacco, and preventing them from becoming regular and, eventually, addicted users. ${ }^{22} 23$ Research from high-income countries generally finds that lower SES populations are more responsive to price than are higher SES populations. ${ }^{17} 24$ Comparable studies from low-income and middle-income countries produce mixed findings, with some finding a socioeconomic gradient in price elasticities and others finding little difference among different SES groups. ${ }^{25} 26$

Finally, several studies examine substitution among tobacco products in response to changes in their relative prices. These studies generally find that part of the reduction in the use of one tobacco product in response to an increase in its price will be offset by increased use of other tobacco products if the prices of these products are not also increased. ${ }^{27} 28$ This substitution highlights the importance of increasing taxes and prices for all tobacco products if the public health benefits of higher prices are one of the motives for tobacco tax increases.

To summarise, a large and growing literature clearly demonstrates that the overall demand for tobacco products is significantly affected by changes in tobacco product taxes and prices, with tobacco use among the young and lower SES populations most affected. These studies demonstrate that price affects all aspects of tobacco consumption, with higher prices preventing initiation among potential users, inducing cessation among current users, and reducing the frequency of consumption and amount consumed by continuing users, while changes in the relative prices of tobacco products will lead to some substitution among products.

\section{TOBACCO TAX REVENUES AND FUNDING FOR TOBACCO CONTROL AND HEALTH PROMOTION}

(NB This section draws on WHO's Technical Manual on Tobacco Tax Administration.) $)^{2}$ As described in the previous two sections, tobacco taxes account for a fraction of tobacco product prices and the percentage reduction in tobacco use resulting from a price increase is smaller than the percentage increase in price in most countries. As a result, tobacco tax increases will increase tax revenues over the short to medium term. (For example, if the price elasticity of cigarette demand is -0.8 and cigarette excises account for half of cigarette prices, a doubling ( $100 \%$ increase) of the cigarette tax will lead to a $50 \%$ increase in cigarette prices and a $40 \%$ reduction in cigarette consumption. The resulting $60 \%$ of consumption will be taxed at twice the original rate, leading to a $20 \%$ increase in revenues.) A growing number of governments have used the revenues generated by tobacco excise tax increases to fund a variety of tobacco control activities and/ or other health promotion efforts, while others have used these revenues to finance parts of their healthcare systems. Around 38 countries around the world earmark part or all their tobacco taxes for specific programmes, but relatively few governments earmark tobacco tax revenues for tobacco control efforts and those that do tend to allocate only a small percentage of tax revenues to these efforts. There are some notable exceptions; California's Proposition 99 that increased the state's cigarette tax from US\$0.10 to US\$0.35 in 1989, for example, dedicated $20 \%$ of new tobacco tax revenues to a comprehensive tobacco control programme and an additional $5 \%$ of the new revenues to tobacco-related research. Several others dedicate tobacco tax revenues to other health-related programmes, but again, this is relatively uncommon and the percentage of revenues dedicated to these programmes is typically small. Thailand is a good example of a country that has done this, with a $2 \%$ surtax on tobacco products and alcoholic beverage that funds the ThaiHealth Foundation, which supports a variety of health promotion activities.

The relatively limited earmarking of tobacco tax revenues for tobacco control and/or other health-related programmes happens despite the evidence demonstrating that this type of earmarking increases political and civil society support for tobacco tax increases. This is likely the result of general opposition to earmarking because of the rigidities it introduces into the budgetary process that limits the use of revenues for alternative purposes, discourages the optimal allocation of resources, and, as a result, reduces social welfare. From a public finance perspective, the strongest support for earmarking results from the principle of benefit taxation and user fees, that states that 
the revenues generated from a tax should be used to provide benefits to those paying the tax. For tobacco taxes, one could argue that tobacco users will be the greatest beneficiaries of tobacco control programmes that promote cessation and prevent initiation of tobacco use, as well as of health promotion and healthcare programmes funded by the tax, given the greater use of healthcare services by tobacco users.

In places where governments have earmarked tobacco tax revenues for tobacco control efforts, the activities supported by these funds have led to additional reductions in tobacco use. In the US, for example, several states use tobacco tax or other tobacco-related revenues to fund comprehensive tobacco control programmes that provide support for cessation efforts, mass media public education campaigns, policy development and implementation and more. ${ }^{29}$ Research shows that increased funding for these programmes leads to reductions in overall tobacco use, adult smoking and youth smoking. ${ }^{30-32}$ In Thailand, $2 \%$ of tobacco and alcohol tax revenues are earmarked for ThaiHealth, supporting a variety of health promotion activities, including tobacco prevention and cessation efforts.

\section{OPPOSITIONAL ARGUMENTS: MYTHS AND FACTS}

While the evidence on the effectiveness of tobacco tax increases in reducing tobacco use and its consequences is clear, as summarised above, a variety of stakeholders including tobacco farmers, tobacco product manufacturers, tobacco product retailers and others often oppose increases in tobacco taxes. (See IARC Handbook 14 for a comprehensive review of the research discussed in this section. ${ }^{6}$ Arguments used in opposition to increased tobacco taxes have generally focused on the economic impact of higher taxes, including their effects on government revenues, businesses and the poor, as well as their role in stimulating illicit trade. However, as demonstrated by extensive research evidence, the arguments about the adverse economic impact of increased tobacco taxes are misleading, overstated, or false. ${ }^{4-633}$ This section briefly reviews these arguments and the evidence on them.

\section{Impact of tobacco tax increases on revenues}

One frequently made claim is that higher tobacco taxes will lead to sharp reductions in governments' tobacco tax revenues as tobacco use falls and tax avoidance and evasion increases. However, as experiences in numerous countries indicate, an increase in tobacco taxes will increase nominal tax revenues in the short to medium term, even when combined with other policies aimed at reducing tobacco use. As tobacco use falls over time, nominal tax revenues will gradually decline, but it will be many years before they fall below their pre-tax-increase level. In contrast, failing to increase tobacco tax rates to keep pace with inflation will lead to reductions in the real value of tobacco tax revenues over time.

With respect to the effects of tobacco tax increases on tobacco tax revenues, the relatively low share of taxes in prices and the less than proportionate reduction in sales in response to a price increase imply that a tobacco tax increase will lead to an increase in tobacco tax revenues. Over time, inflation will erode the value of tobacco tax revenues, unless these taxes are increased often enough to keep pace with inflation. Similarly, as tobacco use declines in response to other tobacco control efforts, revenues from tobacco taxes will also decline, unless taxes are increased periodically. Nevertheless, tax revenues will remain higher many years after a significant tax increase than they were before, even in the wake of a considerable decline in tobacco use. California may be the best example of this, given its cigarette tax increases in 1989 (from 10 to 35 cents), 1994 (from 35 to 37 cents) and 1999 (from 37 to 87 cents), and its sustained comprehensive tobacco control programme funded by earmarked revenues. In the last full fiscal year before the 1989 tax increase, California's gross cigarette tax revenues were just over US\$250 million; in the most recent fiscal year (FY10), California's gross cigarette tax revenues were over US\$845 million. The more than tripling of revenues occurred despite tax paid cigarette sales falling by more than $60 \%$ as a result of the tax and price increases, activities funded by earmarked tax revenues and strengthening of other tobacco control policies.

\section{Impact of tobacco control policies on business}

A second argument commonly used in opposition to higher tobacco taxes is that these policies will reduce business activity and cause significant job losses. This argument is based on the notion that some involvement of a business with tobacco implies a dependence on tobacco (eg, that retailers that sell tobacco products or advertising agencies that develop marketing campaigns are financially dependent on the continued use of these products). The reality is that very few tobacco-related jobs are actually dependent on tobacco (most notably tobacco growing and tobacco product manufacturing) and that the economic contribution from tobacco-dependent activities is very small and declining in most countries. ${ }^{34}$

While the significant declines in tobacco use that result from higher tobacco taxes do lead to reductions in employment in and the economic contribution of the tobacco-dependent sectors of the economy, these losses are typically more than offset by increased economic activity and employment in other sectors as the money once spent on tobacco is now spent on other goods and services and as governments spend the increased tax revenues. ${ }^{6} 35$ This net positive impact results from the relatively capital-intensive nature of tobacco production relative to the more labour-intensive production of other goods and services.

\section{Impact of tobacco control policies on the poor}

The argument that increased tobacco taxes will adversely impact the poor is frequently used in opposition to proposed tax increases and is based on the evidence that existing tobacco taxes are regressive (ie, that those on lower incomes bear a disproportionate share of the tobacco tax burden). The regressivity of existing tobacco taxes results, in part, from the greater concentration of smoking among the lowest income populations, one result of which is that these populations also bear a disproportionate share of the burden of disease caused by tobacco.

The regressivity of existing taxes, however, does not necessarily imply that tax increases are regressive as well. In many countries, tobacco use among the lowest income/SES populations is most responsive to price, while use among the highest income/SES populations is least responsive. Thus, a tax increase that raises tobacco product prices will lead to the largest declines in smoking among the lowest income persons, and the burden of tax increase will fall more heavily on higher income consumers whose smoking behaviour changes little in response to the tax increase. $^{6}$

It is true, however, that low-income persons who continue to use tobacco following a tax increase will be adversely affected. To the extent that the new revenues generated by tobacco tax increases are allocated to programmes targeting the poor, including tobacco control programmes, this concern is at least partially alleviated. For example, several governments have 
earmarked tobacco tax revenues for programmes that provide cessation products and counselling to low income smokers interested in quitting, while many focus on reducing incomerelated and other disparities in tobacco use and its consequences. Still others have dedicated new tobacco tax revenues to public health insurance programmes for low-income populations and/ or other poverty alleviation efforts. ${ }^{2}$

\section{Tobacco taxation and black markets}

A final argument used in opposition to increased tobacco taxes is that the higher taxes will stimulate significant tax avoidance among tobacco users and create a black market in tobacco products, resulting in lost tax revenues and fewer public health benefits. While it is true that higher taxes do create greater incentives for tax avoidance and evasion, the extent of the problem has been significantly overstated. In addition, other factors such as the extent of corruption, informal distribution channels and the presence of organised criminal networks can be more important determinants of illicit tobacco trade than are tobacco taxes. One recent review, for example, estimates that $11.6 \%$ of the global cigarette market is illicit, with a relatively higher share in low-income, low-tax countries and a lower share in high-income, higher-tax countries. ${ }^{36}$

As discussed in the World Bank's Curbing the Epidemic, tobacco tax increases will still generate increases in tax revenues and reductions in tobacco use, even when tax avoidance and evasion increase. ${ }^{4}$ The World Bank states that the appropriate response is not to forego tax increases, but instead to crack down on illicit trade in tobacco products. Governments that have strengthened their tax administration, increased enforcement, imposed swift and severe penalties, and worked collaboratively with others in their region have been effective in reducing tax avoidance and evasion and in maximising the health and revenue impact of higher tobacco taxes. ${ }^{6}$

\section{BEST PRACTICES IN TOBACCO TAXATION}

(NB This section draws heavily from WHO's Technical Manual on Tobacco Tax Administration. $)^{2}$ Based on the accumulated empirical evidence and published literature described briefly above, several 'best practices' in tobacco taxation have emerged. ${ }^{2}$ These best practices emphasise the health impact of tobacco taxes while also recognising the importance of revenue objectives and represent a roadmap that most countries can readily implement.

\section{Use tobacco excise tax increases to achieve the public health goal of reducing the death and disease caused by tobacco use Extensive economic and other research has clearly demonstrated the effectiveness of higher tobacco product taxes and prices in reducing tobacco use and its consequences, particularly among the poor and the young. Given this evidence, increases in tobacco taxes are central to the WHO FCTC.}

\section{Set tobacco excise tax levels so that they account for at least $\mathbf{7 0} \%$ of the retail prices for tobacco products}

Tobacco excise taxes in nearly all countries account for $<70 \%$ of retail prices, with taxes in most accounting for less than half of retail prices. Raising tobacco taxes so that they account for at least $70 \%$ of retail prices would lead to significant price increases, induce many current users to quit and deter numerous young people from taking up tobacco use, leading to large reductions in the death and disease caused by tobacco use. It is important to note that this best practice focuses on tobacco excise taxes (or other tobacco-specific taxes) and not on all taxes applied to tobacco products, given that tobacco-specific taxes are the ones that lead to increases in the relative prices of tobacco products and to reductions in tobacco use. In the few countries that have already reached this threshold, further increases in tobacco taxes in line with other best practices described below would be appropriate.

\section{Simpler is better}

Complex tax structures are difficult to administer, create opportunities for tax avoidance and evasion, and are less effective in achieving public health and revenue goals. In countries with complex tax structures, an appropriate transition strategy involves reducing the variations in taxes over time with the aim of implementing a single uniform tax on a given tobacco product. Countries with multiple tiers based on price should reduce the number of tiers over time, eventually ending up with a single uniform tax. Similarly, countries that levy different taxes based on product characteristics should reduce and eventually eliminate these differential taxes.

\section{Rely more on specific tobacco excises as the share of excise taxes in retail prices increases}

Greater reliance on specific excise taxes maximises the impact of tobacco taxes on public health by reducing the gap in prices between premium and low priced alternatives, thereby limiting opportunities for users to switch down in response to tax increases. Applying the same specific tax to all brands of a given tobacco product also sends the clear message that all brands are equally harmful. For countries that currently rely on an ad valorem tax or a mix of ad valorem and specific taxes, an appropriate first step would be to set a sizeable specific tax that applies to all brands with an ad valorem tax applied above this. Over time, the ad valorem rate could be reduced with greater increases in the specific tax so that the total tax increases as a share of retail price, and so that the specific tax accounts for a greater share of the total excise tax.

\section{Rely more on excise taxes than on import duties}

The effectiveness of import duties in generating higher revenues and increasing retail prices has been decreasing as countries adopt bilateral, regional and global trade agreements. Consequently, relying on specific tobacco excises would ensure the health impact of tobacco taxes as well as the sustainability of tobacco tax revenues. For countries that currently rely heavily on import duties from tobacco products, an appropriate transition strategy would be to reduce import duties over time while adopting and increasing specific tobacco excises so that total taxes on tobacco products are increasing.

\section{Adopt comparable taxes and tax increases on all tobacco products}

Increasing excise taxes on some tobacco products but not on others results in changes in the relative prices of these products that induce substitution towards relatively less expensive products. Comparable increases in the taxes on all tobacco products maximise the public health impact of tobacco tax increases by minimising opportunities for substitution.

\section{Eliminate tax and duty free sales of tobacco products}

Article 6 of the WHO FCTC calls for the prohibition (or restriction) of sales and importations by international travellers of tax and duty free tobacco products. Doing so increases the public health impact of higher tobacco taxes by raising all 
tobacco product prices and by reducing opportunities for tax avoidance while at the same time generating additional revenues.

\section{Automatically adjust specific tobacco taxes for inflation}

Unless regularly adjusted, the real value of specific tobacco taxes will fall over time as general price levels increase. When this happens, the real value of tobacco taxes revenues falls and the effectiveness of the tax in reducing tobacco use and promoting health will be diminished. Governments can avoid this by establishing a mechanism for automatically adjusting specific taxes so as to keep pace with inflation.

\section{Increase tobacco taxes by enough to reduce the affordability of tobacco products}

In many low-income and middle-income countries, tobacco use increases as national income rises and national income is rising faster than tobacco product prices, so that these products are becoming more affordable. In order to maximise the health impact of higher tobacco taxes, governments should raise taxes so as to raise prices and reduce the affordability of tobacco products by ensuring that real price increases exceed increases in real incomes.

\section{Include tobacco excise tax increases as part of a comprehensive strategy to reduce tobacco use}

In addition to higher tobacco taxes, governments should adopt a comprehensive strategy for reducing tobacco use that includes, but is not limited to, comprehensive smoke-free air policies, total bans on tobacco company marketing activities, strong warnings about the consequences of tobacco use, broad efforts to help current users quit and mass media public education campaigns. A comprehensive strategy leads to greater reductions in the consequences of tobacco use, builds public and political support for higher taxes and maximises the effectiveness of tax increases in achieving health objectives.

\section{Use a portion of tobacco tax revenues to support other tobacco control and/or health promotion efforts}

Increases in tobacco taxes generate revenues that can be used to support a variety of activities, including other tobacco control interventions and health promotion efforts that result in greater reductions in tobacco use than from the tax increase alone. Experiences in many countries show that public support for higher taxes is greater when some of the increased revenues are used to support such programmes. While hard earmarking (legally binding earmarking) of tobacco tax revenues for tobacco control and other health promotion efforts may be infeasible in some countries, soft earmarking (non-binding but accepted earmarking) of tax revenues should be possible in all countries.

Do not view low taxes and prices for some tobacco products as a 'pro-poor' policy

Keeping tobacco taxes and prices low on some products, so as to ensure affordability of these products for the poor leads to greater tobacco use among the poor, causing them to bear a disproportionate share of the burden of the health and economic consequences of tobacco use and increasing the risk of future poverty. High tobacco taxes on all tobacco products lead to greater reductions in tobacco use among the poor and to a progressive distribution of the health and economic benefits that result: a truly 'pro-poor' policy.
Do not allow concerns about the regressivity of higher tobacco taxes to prevent tobacco tax increases

Tobacco tax increases can be progressive given differences in price responsiveness by income, with higher taxes increasing the overall share of tobacco taxes paid by higher income groups. If concerns about the impact of tax increases on the poor remain, these can be offset by using revenues generated from a tax increase to support efforts to help poor tobacco users quit, other health promotion efforts targeting the poor and/or other programmes directed to those in poverty.

\section{Do not allow concerns about employment impact to prevent tobacco tax increases}

Reductions in tobacco-dependent employment following tax increases are offset by increases in employment in other sectors as spending on tobacco products is replaced by spending on other goods and services. In most countries, it is likely that there will be either no net impact on jobs or, more likely, a small increase in jobs following a tax increase. If concerns exist about job losses in tobacco-dependent sectors, using a portion of new tobacco tax revenues to move tobacco farmers into other crops and/or to retrain those employed in tobacco product manufacturing for work in other sectors can reduce these concerns

\section{Do not allow concerns about the inflationary impact of higher} tobacco taxes to deter tax increases

In most countries, tobacco taxes are a low share of tobacco product prices and/or little weight is given to tobacco product prices in computing national price indices, implying that tobacco tax increases will generally have a small impact on inflation. In countries where tobacco products have more significant weight in national price indices, a significant tax increase will have a greater impact on inflation. ${ }^{2}$ If there are concerns about the inflationary impact of a tobacco tax increase given that wages or some government spending may be tied to a price index, governments can reduce these concerns by using a price index that excludes tobacco products. While this makes the price index less representative of consumer spending, several governments already exclude a variety of controversial products, including tobacco products, alcoholic beverages and gaming from the price index they use for adjusting wages and/or other government spending.

\section{Strengthen tobacco tax administrators' capacity to monitor} tobacco product markets and evaluate the impact of tobacco tax increases

Regardless of how well the tax system is integrated between the tobacco manufacturers and tax administrators, tax authorities should 'trust but verify' by adopting technologies for monitoring the production and distribution of tobacco products, maintaining physical control over these products as they move through the distribution chain and auditing taxpayer account books periodically. If one does not already exist, a tobacco excise department should be established. This department should collaborate with Customs to minimise non-compliance and monitor trade, as well as with tax authorities from neighbouring countries and regional and global organisations. It should also maintain a comprehensive database for use in assessing tobacco product markets, conducting demand analyses and evaluating current tobacco taxes and the impact of increases in these taxes. Such efforts will be most effective when done in cooperation and collaboration. 


\section{Adopt new technologies to strengthen tobacco tax administration and minimise tax avoidance and evasion}

Up-to-date technologies should be adopted in order to increase efficiency of tax collection and minimise tax avoidance and evasion. These new technologies include more sophisticated, harder to counterfeit tax stamps and tracking-and-tracing systems that can be used to follow tobacco products through the distribution chain. When needed, adoption of these technologies could be financed by small increases in tobacco excise taxes; in most countries, the adoption of these technologies would more than pay for itself through the revenues collected on products for which taxes would otherwise not have been paid.

\section{Strengthen tobacco tax administrators' capacity by licensing all involved in tobacco product manufacturing and distribution}

Licensing of all involved in tobacco production and distribution facilitates monitoring of tobacco product markets, makes it easier to identify illicit tobacco products and increases administrators' ability to identify and penalise those engaged in tax evasion. This is particularly true when done in combination with the adoption of the technologies discussed above.

\section{Ensure certain, swift and severe penalties for those caught engaging in illicit trade in tobacco products}

Strong tobacco tax enforcement increases the likelihood that those engaging in illicit trade will be caught, while high administrative penalties raise the swiftness and severity of punishment for illegal activity. Stronger enforcement efforts would likely pay for themselves through increased taxes collected on previously untaxed products. Enforcement efforts are most effective when targeted at those running the illicit operation rather than focused on those at the end of the illicit product distribution chain.

\section{CONCLUSIONS}

Tobacco excise taxes are a powerful tool for improving health while at the same time being a reliable source of government revenues. Significant increases in tobacco taxes that result in higher tobacco product prices encourage current tobacco users to stop using, prevent potential users from taking up tobacco use and reduce consumption among those that continue to use, with the greatest impact on the young and the poor. As a result, higher taxes are effective in reducing the death, disease and economic costs caused by tobacco use. The positive health impact is even greater when some of the revenues generated by tobacco tax increases are used to support tobacco control, health promotion and/or other health-related activities and programmes.

The experiences with the variety of and changes to taxes and tax structures applied to tobacco products around the world provide an extensive evidence base for identifying best practices in tobacco taxation. These best practices include: adoption of a relatively simple tax system that applies equivalent taxes to all tobacco products; increases in these taxes that exceed increases in consumer prices and incomes so as to reduce the affordability of tobacco products; minimisation of incentives for tobacco users to switch to cheaper brands or products in response to tax increases; and reduced opportunities for tax avoidance and evasion. This type of tax system will have the greatest public health impact, while at the same time producing a reliable stream of tax revenues. Such a system will be most effective when combined with strong tax administration, including the use of a state-of-the-art monitoring, tracking and tracing system

\section{What this paper adds}

- Extensive economic research clearly demonstrates that increases in tobacco excise taxes are a highly effective tobacco control strategy. Higher taxes that increase prices lead adult tobacco users to quit, prevent former users from restarting, deter youth uptake of tobacco use and reduce consumption of tobacco products by continuing users.

- At the same time, increases in tobacco taxes raise revenues that can be used to support other efforts to reduce tobacco use, adding to the public health impact of the higher taxes. Oppositional arguments about the economic effects of tobacco tax increases are either false or overstated.

- This paper reviews the salient issues related to the effectiveness of tobacco taxation as a tobacco control strategy, providing a concise summary of the voluminous literature on tobacco taxes, their impact on tobacco use and related outcomes, the economic impact of increased tobacco taxes and best practices in tobacco tax administration.

that includes high-tech tax stamps and licensing of all involved in the production and distribution of tobacco products, coupled with adequate enforcement and swift, severe penalties on violators.

Despite the evidence on the beneficial revenue and public health impact of higher tobacco taxes, there are many barriers to increasing tobacco taxes that are often based on economic arguments. These range from concerns about the macroeconomic effects of higher taxes (eg, on employment and inflation) to concerns about the regressivity of tobacco taxes and the impact of higher taxes on the poor. In general, these arguments are false or overstated. Increasing tobacco taxes will not lead to net job losses in most countries, but rather to job gains as resources are shifted to more labour intensive sectors of the economy. Similarly, inflationary fears are overstated, with tax increases having little impact on inflation in most countries. Concerns about the impact on the poor are offset by the progressive nature of the health benefits of reduced tobacco use in response to higher taxes and can be further offset by using some of the revenues generated from these taxes for programmes targeting the poor. While the global evidence demonstrate that this can be helpful, local data and research demonstrating the positive public health and economic impact of higher tobacco taxes will be particularly useful in overcoming these arguments.

\section{Competing interests None.}

Provenance and peer review Commissioned; internally peer reviewed.

\section{REFERENCES}

1. Smith A, Canaan E, eds. An Inquiry into the Nature and Causes of the Wealth of Nations. Chicago: University of Chicago Press, 1976.

2. World Health Organization. WHO Technical Manual on Tobacco Tax Administration. Geneva: World Health Organization, 2010. http://www.who.int/ tobacco/publications/tax_administration/en/index.html

3. World Health Organization. WHO Framework Convention on Tobacco Control. Geneva: World Health Organization, 2003.

4. World Bank. Curbing the Epidemic: Governments and the Economics of Tobacco Control. Washington DC: The International Bank for Reconstruction and Development/ The World Bank, 1999. http://www.worldbank.org/tobacco

5. Jha P, Chaloupka FJ, eds. Tobacco Control in Developing Countries. Oxford: Oxford University Press, 2000. http://www.worldbank.org/tobacco

6. International Agency for Research on Cancer. IARC Handbooks of Cancer Prevention, Tobacco Control, Volume 14: Effectiveness of Tax and Price Policies in Tobacco Control. Lyon, France: International Agency for Research on Cancer, 2011. http://www.iarc.fr/en/publications/list/handbooks/ 
7. World Health Organization. WHO Report on the Global Tobacco Epidemic, 2011. Geneva: World Health Organization, 2011.

8. Chaloupka FJ, Pack RM, Tauras JA, et al. Cigarette Excise Taxation: The Impact of Tax Structure on Prices, Revenues, and Cigarette Smoking. National Bureau of Economic Research Working Paper Number 16287. Cambridge MA: National Bureau of Economic Research, 2009.

9. Warner KE. Cigarette smoking in the 1970's: the impact of the antismoking campaign on consumption. Science 1981;211:729-31.

10. Duffy M. Advertising and the consumption of tobacco products and alcohol drink: a system-wide analysis. Scott J Polit Econ 1991;38:369-85.

11. Gruber $\mathbf{J}$, Köszegi B. Is addiction rational? Theory and evidence. $0 \mathrm{~J}$ Econ 2001:116:1261-303

12. Keeler TE, Hu TW, Barnett PG, et al. Taxation, regulation, and addiction: a demand function for cigarettes based on time-series evidence. J Health Econ 1993:12:1-18.

13. Becker GS, Grossman M, Murphy KM. An empirical analysis of cigarette addiction. Am Econ Rev 1994;84:396-418.

14. Hu TW, Mao Z. Economic Analysis of Tobacco and Options for Tobacco Control: China Case Study. Health, Nutrition Population Discussion Paper, Economics of Tobacco Control No.3. Washington DC: World Bank and WHO, 2002

15. John RM. Price elasticity estimates for tobacco products in India. Health Policy Plan 2008;23:200-9

16. Lewit EM, Coate D. The potential for using excise taxes to reduce smoking. J Health Econ 1982:1:121-45.

17. Farrelly MC, Bray JW, Pechacek T, et al. Response by adults to increases in cigarette prices by sociodemographic characteristics. South Econ J 2001:68:156-65.

18. Douglas S. The duration of the smoking habit. Econ Inq 1998;36:49-64.

19. Tauras JA. Public policy and smoking cessation among young adults in the United States. Health Policy 2004;68:321-32.

20. Jimenez-Ruiz JA, Saenz de Miera B, Reynales-Shigematsu LM, et al. The impact of taxation on tobacco consumption in Mexico. Tob Control 2008:17:105-10.

21. Kyaing NN. Tobacco Economics in Myanmar. HNP Discussion Paper. Washington DC: The World Bank, 2003.

22. Lewit EM, Coate D, Grossman M. The effects of government regulation on teenage smoking. J Law Econ 1981;24:545-69.

23. Tauras JA, Johnson LD, O'Malley PM. Effects of Price and Access Laws on Teenage Smoking Initiation: A National Longitudinal Analysis. Cambridge MA: National Bureau of Economic Research, 2001. Working Paper Number 8331
24. Townsend J, Roderick P, Cooper J. Cigarette smoking by socioeconomic group, sex, and age: effects of price, income and health publicity. BMJ 1994;309:923-6.

25. Sayginsoy 0, Yurekli A, de Beyer J. Cigarette Demand, Taxation, and the Poor: A Case Study of Bulgaria. HNP Discussion Paper. Washington DC: The World Bank, 2002.

26. Önder Z. The Economics of Tobacco in Turkey: New Evidence and Demand Estimates. HNP Discussion Paper. Washington DC: The World Bank, 2002.

27. Laxminarayan $\mathbf{R}$, Deolalikar A. Tobacco initiation, cessation, and change: evidence from Vietnam. Health Econ 2004;13:1191-201.

28. Ohsfeldt RL, Boyle RG, Capilouto El. Tobacco taxes, smoking restrictions, and tobacco use. In: Chaloupka FJ, Grossman M, Bickel WK, et al, eds. The Economic Analysis of Substance Use and Abuse: An Integration of Econometric and Behavioral Economic Research. Chicago: University of Chicago Press for the National Bureau of Economic Research, 1999.

29. U.S. Centers for Disease Control and Prevention. Best Practices for Comprehensive Tobacco Control Programs. Atlanta GA: U.S. Department of Health and Human Services, Public Health Service, Centers for Disease Control and Prevention, National Center for Chronic Disease Prevention and Health Promotion, Office on Smoking and Health, 2007.

30. Farrelly MC, Pechacek TF, Chaloupka FJ. The impact of tobacco control program expenditures on aggregate cigarette sales: 1981-2000. J Health Econ 2003:22:843-59.

31. Farrelly MC, Pechacek TF, Thomas KY, et al. The impact of tobacco control programs on adult smoking. Am J Public Health 2008;98:304-9.

32. Tauras JA, Chaloupka FJ, Farrelly MC, et al. State tobacco control spending and youth smoking. Am J Public Health 2005;95:338-44.

33. Warner KE. The economics of tobacco: myths and realities. Tob Control 2000:9:78-89.

34. Jacobs R, Gale HF, Capehart TC, et al. The supply-side effects of tobacco-control policies. In: Jha P, Chaloupka FJ, eds. Tobacco Control in Developing Countries. Oxford: Oxford University Press, 2000

35. Warner KE, Fulton GA, Nicolas P, et al. Employment implications of declining tobacco product sales for the regional economies of the United States. JAMA 1996;275:1241-6.

36. Joossens L, Merriman D, Ross $\mathrm{H}$, et al. How Eliminating the Global Illicit Cigarette Trade Would Increase Tax Revenue and Save Lives. Paris: The International Union Against Tuberculosis and Lung Disease, 2009. 


\section{Competing interests None.}

Contributors All authors included on the paper fulfil the criteria of authorship.

Provenance and peer review Not commissioned; externally peer reviewed.

\section{REFERENCES}

1. US Public Health Service, Office of the Surgeon General. The Health Consequences of Involuntary Exposure to Tobacco Smoke: A Report of the Surgeon General: Executive Summary. Rockville, MD: US Department of Health and Human Services, Public Health Service, Office of the Surgeon General, 2006.

2. Muller T. Breaking the Cycle of Children's Exposure to Tobacco Smoke. London: British Medical Association, 2007.

3. McNabola A, Gill LW. The control of secondhand smoke: a policy review. Int $\mathbf{J}$ Environ Res Public Health 2009;6:741-58.

4. Brownson RC, Figgs LW, Caisley LE. Epidemiology of secondhand smoke exposure. Oncogene 2002;21:7341-8.

5. International Agency for Research on Cancer. Tobacco Smoke and Involuntary Smoking. IARC Monographs on the Evaluation of Carcinogenic Risks to Humans. vol. 83. Lyon, France: IARC, 2004.

6. International Agency for Research on Cancer. Some Industrial Chemicals and Dyestuffs. Monographs on the Evaluation of Carcinogenic Risks to Humans. vol. 29 Lyon, France: IARC, 1982.

7. Chang JS. Parental smoking and childhood leukemia. Methods Mol Biol 2009;472:103-37.

8. US Environmental Protection Agency. Toxicity and Exposure Assessments for Children's Health. Benzene TEACH Chemical Summary. http://www.epa.gov/teach/ chem_summ/BENZ_summary.pdf (accessed 31 Mar 2010).

9. Fustinoni S, Consonni D, Campo L, et al. Monitoring low benzene exposure: comparative evaluation of urinary biomarkers, influence of cigarette smoking, and genetic polymorphisms. Cancer Epidemiol Biomarkers Prev 2005;14:2237-44

10. Lovreglio P, Barbieri A, Carrieri $M$, et al. Validity of new biomarkers of internal dose for use in the biological monitoring of occupational and environmental exposure to low concentrations of benzene and toluene. Int Arch Occup Environ Health 2010;83:341-56

11. Protano C, Guidotti M, Manini P, et al. Benzene exposure in childhood: role of living environments and assessment of available tools. Environ Int 2010;36:779-87.

12. Haufroid V, Lison D. Urinary cotinine as a tobacco-smoke exposure index: a minireview. Int Arch Occup Environ Health 1998;71:162-8.

13. Vitali M, Ensabella F, Stella D, et al. Exposure to organic solvents among handicraft car painters: a pilot study in Italy. Ind Health 2006:44:310-17.

14. Manini P, De Palma G, Andreoli R, et al. Biological monitoring of low benzene exposure in Italian traffic policemen. Toxicol Lett 2008;181:25-30.

15. Henry RJ. Clinical chemistry principle and techniques (2nd edn). New York: Harper \& Row, 1974

16. International Agency for Research on Cancer. IARC Handbooks of Cancer Prevention, Tobacco Control: Evaluating the Effectiveness of Smoke-Free Policies. vol. 13. Lyon, France: IARC, 2009.

17. Kabir Z, Manning PJ, Holohan J, et al. Active smoking and secondhandsmoke exposure at home among Irish children, 1995-2007. Arch Dis Child 2010;95:42-5.

18. Borland $\mathbf{R}$, Yong $\mathrm{HH}$, Cummings $\mathrm{KM}$, et al. Determinants and consequences of smoke-free homes: findings from the International Tobacco Control (ITC) Four Country Survey. Tob Control 2006;15(Suppl 3):iii42-50.

19. Soliman S, Pollack HA, Warner KE. Decrease in the prevalence of secondhand smoke exposure in the home during the 1990s in families with children. Am J Public Health 2004:94:314-20.

20. Matt GE, Quintana PJ, Hovell MF, et al. Households contaminated by secondhand smoke: sources of infant exposures. Tob Control 2004;13:29-37.

21. Winickoff JP, Friebely J, Tanski SE, et al. Beliefs about the health effects of "thirdhand" smoke and home smoking bans. Pediatrics 2009;123:e74-9.

22. Invernizzi G, Ruprecht A, De Marco C, et al. Residual tobacco smoke: measurement of its washout time in the lung and of its contribution to secondhand smoke. Tob Control 2007;16:29-33.

23. Jarvis MJ, Mindell J, Gilmore A, et al. Smoke-free homes in England: prevalence trends and validation by cotinine in children. Tob Control 2009:18:491-5.

\section{Corrections}

Moodie C, Mackintosh AM, Hastings G, et al. Young adult smokers' perceptions of plain packaging: a pilot naturalistic study. Tob Control 2011;20:367-73. doi:10.1136/tc.2011.042911.

The funding statement in this article should have read:

Funding Cancer Research UK; UK Centre for Tobacco Control Studies fund two of the authors (GH and $\mathrm{AF})$.

Tobacco Control 2012:21:329. doi:10.1136/tc.2011.042911corr

Chaloupka FL, Yurekli A, Fong GT. Tobacco taxes as a tobacco control strategy. Tob Control 2012;21:172-180

The following competing interest statement should have been included with this article:

Competing interests The authors alone are responsible for the views expressed in this publication and they do not necessarily represent the decisions or the policies of the World Health Organization

Tobacco Control 2012:21:329. doi:10.1136/tobaccocontrol-2011-050417corr1

Daynard RA. Allying tobacco control with human rights: invited commentary. Tob Control 2012;21:213-214

The author list for this article should read Richard A Daynard, Rangita de Silva de Alwis and Mark Gottlieb.

Rangita de Silva de Alwis. Senior Consultant for International Programs at the Public Health Advocacy Institute at Northeastern University School of Law and Senior Adviser for International Programs at the Wellesley Centers for Women at Wellesley College. Mark Gottlieb. Executive Director of the Public Health Advocacy Institute at Northeastern University School of Law. 